\title{
Bioequivalence Study of Modified-Release Gliclazide Tablets in Healthy Volunteers
}

\author{
Noppamas Rojanasthien, Thatree Autsavakitipong, Boonyium Kumsorn, \\ Maleeya Manorot, and Supanimit Teekachunhatean \\ Department of Pharmacology, Faculty of Medicine, Chiang Mai University, Chiang Mai 50200, Thailand \\ Correspondence should be addressed to Supanimit Teekachunhatean, steekach@med.cmu.ac.th
}

Received 26 June 2012; Accepted 16 August 2012

Academic Editors: G. M. Campo, T. B. Vree, K. Wada, and S.-N. Wu

Copyright (c) 2012 Noppamas Rojanasthien et al. This is an open access article distributed under the Creative Commons Attribution License, which permits unrestricted use, distribution, and reproduction in any medium, provided the original work is properly cited.

This study was aimed to investigate bioequivalence of modified-release $30 \mathrm{mg}$ gliclazide tablets in 18 healthy Thai volunteers. A test product, Glycon MR (Siam Bheasach, TH), was compared with a reference product, Diamicron MR (Servier, France). The study was performed under a single-dose, two-treatment, two-period, and two-sequence crossover design in fasted and fed conditions with a washout period of 2 weeks. Blood samples were collected for $72 \mathrm{~h}$ after drug administration. Drug plasma concentrations were determined by HPLC with a UV detector. Analysis of pharmacokinetic characteristics was based on a noncompartmental model. The logarithmically transformed data of $C_{\max }$ and AUCs were analyzed for $90 \%$ confidence intervals using ANOVA. The test product gave slightly higher $C_{\max }$ in both conditions and shorter $T_{\max }$ in the fed condition. However, there is no significant difference in pharmacokinetic characteristics between both products under fasted and fed conditions. Effect of food was not significantly observed. The $90 \%$ confidence intervals were within the acceptance criteria of $0.80-1.25$ regardless of the food effect, indicating bioequivalence between the two products on the rate and extent of gliclazide MR absorption without regard to meals.

\section{Introduction}

Gliclazide is a second-generation sulfonylurea, an oral hypoglycemic agent used in the treatment of noninsulin dependent diabetes mellitus. It decreases blood glucose level by stimulating insulin secretion from pancreatic $\beta$-cells and increasing sensitivity of the $\beta$-cells to a glucose stimulus [1]. Moreover, long-term treatment of gliclazide improves insulin-mediated glucose utilization and potentiates the post-receptor insulin sensitive pathway $[1,2]$. It may have advantages in reducing platelet aggregation and slowing the progression of diabetic retinopathy [3-5].

Gliclazide is a weak acid compound with high lipophilicity and has $\mathrm{pH}$-dependent solubility [1]. The drug is insoluble under acidic condition in the stomach and its solubility increases with increasing $\mathrm{pH}$ in the intestinal region. Due to its lipophilicity, drug absorption is limited by the ability of the drug to be released from the dosage form. Immediate release preparations of gliclazide have been marketed for a long time with the general administration of twice daily taken with the main meals. Recently, a new formulation of modified release gliclazide (Gliclazide MR) has been developed to a progressive delivery of the short acting gliclazide, intending to be administered once daily. This formulation gains more interest as it gives better diabetic control and improves patient compliance $[6,7]$.

Modified release dosage forms of gliclazide are generally tailored in a hydrophilic matrix base which expands once in contact with gastrointestinal fluid to form a gel layer which gradually deliberates the drug over $24 \mathrm{~h}$ [8]. Contrary to other modified release formulations, the presence of food has no influence on the drug absorption from gliclazide MR [9]. This property proves a superiority of gliclazide MR to the conventional tablets where the variation in bioavailability is commonly reported [10].

Gliclazide MR shows linear pharmacokinetic properties over the dose range of $15-120 \mathrm{mg}$ and low individual variability at $16 \%$ [8]. After oral administration, gliclazide 


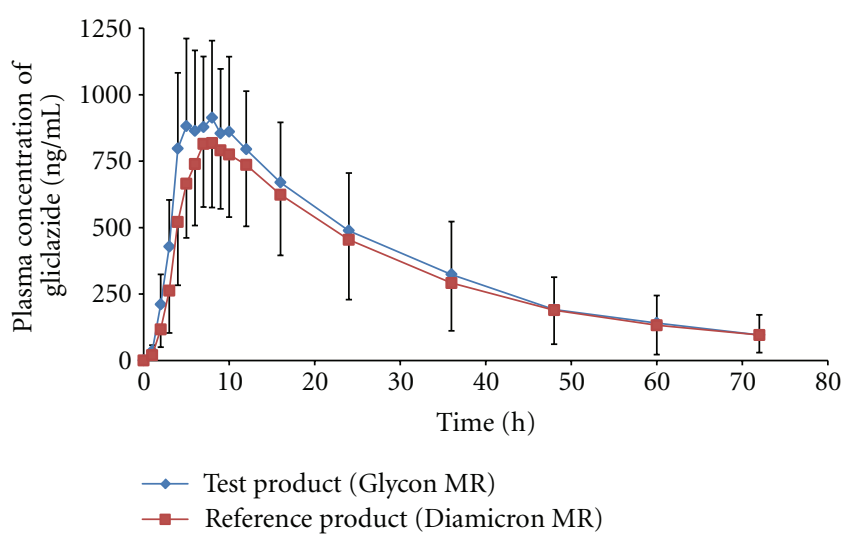

Figure 1: Mean plasma concentration of gliclazide after administration of $30 \mathrm{mg}$ gliclazide MR tablets of the test product, Glycon $\mathrm{MR}$, and the reference product, Diamicron MR, in 18 volunteers under fasted condition.

TABle 1: Demographic characteristics of the volunteers administered with $30 \mathrm{mg}$ gliclazide MR tablets.

\begin{tabular}{lcc}
\hline Demographic characteristic & Group number 1 & Group number 2 \\
\hline Age $(\mathrm{y})$ & $29 \pm 6.28$ & $28.22 \pm 7.33$ \\
Height $(\mathrm{m})$ & $1.72 \pm 0.04$ & $1.67 \pm 0.02$ \\
Weight $(\mathrm{kg})$ & $65.70 \pm 5.11$ & $62.80 \pm 4.70$ \\
Body mass index $\left(\mathrm{kg} / \mathrm{m}^{2}\right)$ & $22.25 \pm 1.62$ & $22.52 \pm 1.77$ \\
\hline
\end{tabular}

concentration increases during the first $6 \mathrm{~h}$, followed by a plateau-shaped curve from the 6 th to the 12 th $\mathrm{h}$, then progressively declines in a monoexponential manner with terminal half-life $\left(t_{1 / 2}\right)$ of $13-16 \mathrm{~h}[8,9]$. The drug is highly bound to albumin (95\%) and extensively metabolized in the liver to at least 7 metabolites which show no hypoglycemic activity [2]. After being metabolized, approximately $60-70 \%$ of drug is excreted in urine and another $10-20 \%$ in feces. Drug clearance is $0.9 \mathrm{~L} / \mathrm{h}$ with the distribution volume of $19 \mathrm{~L}$. An initial recommended dose is $30 \mathrm{mg}$ once daily taken with breakfast, and the daily dose can be monitored in the range of $30-120 \mathrm{mg}$. Dose titration should be carried out in the steps of $30 \mathrm{mg}$, according to the fasted blood glucose response and each step should last for at least 2 weeks [8].

Adverse events of gliclazide MR are mild and transient which not requiring discontinuation of the therapy. The incidence and type of adverse events are similar in the treatment with gliclazide MR or gliclazide $80 \mathrm{mg}$ [7]. The most frequent adverse events include arthralgia, arthritis, back pain, and bronchitis. Complication of cardiovascular ATP-sensitive potassium channel interaction generally found in diabetes patients has not been observed at therapeutic concentrations with gliclazide MR treatment and antioxidant properties of the drug are independent of the glycemic control [8].

To accomplish bioequivalence approach, the two orally administered drug products are considered to be bioequivalent when the same rate and extent of the absorption are demonstrated. Many research groups have reported bioavailability of gliclazide MR based on pharmacokinetic studies in
TABLE 2: Pharmacokinetic characteristics of gliclazide from 18 volunteers following a single oral administration of $30 \mathrm{mg}$ gliclazide MR tablets under fasted condition.

\begin{tabular}{lcc}
\hline $\begin{array}{l}\text { Pharmacokinetic } \\
\text { parameter }\end{array}$ & $\begin{array}{c}\text { Test product } \\
\text { (Glycon MR) }\end{array}$ & $\begin{array}{c}\text { Products } \\
\text { Reference product } \\
\text { (Diamicron MR) }\end{array}$ \\
\hline$T_{\max }(\mathrm{h})$ & $8.22 \pm 3.95$ & $7.72 \pm 1.96$ \\
$C_{\max }(\mathrm{ng} / \mathrm{mL})$ & $1,016.66 \pm 283.48$ & $898.67 \pm 224.45$ \\
$\mathrm{AUC}_{0-t}(\mathrm{ng} \cdot \mathrm{h} / \mathrm{mL})$ & $27,305.13 \pm 10811.90$ & $25,224.32 \pm 11244.21$ \\
$\mathrm{AUC}_{0-\infty}$ & $30,172.13 \pm 13609.32$ & $28,003.82 \pm 13924.33$ \\
$(\mathrm{ng} \cdot \mathrm{h} / \mathrm{mL})$ & $17.83 \pm 5.40$ & $15.50 \pm 5.69$ \\
$t_{1 / 2}(\mathrm{~h})$ & $0.04 \pm 0.01$ & $0.04 \pm 0.02$ \\
$K_{e}\left(\mathrm{~h}^{-1}\right)$ & &
\end{tabular}

TABle 3: $90 \%$ Confidence intervals of $C_{\max }, \mathrm{AUC}_{0-t}$, and $\mathrm{AUC}_{0-\infty}$ of the test product compared to the reference product under fasted and fed conditions.

\begin{tabular}{lcc}
\hline \multirow{2}{*}{ Pharmacokinetic parameter } & \multicolumn{2}{c}{$90 \%$ Confidence interval } \\
& Fasted condition & Fed condition \\
\hline$C_{\max }$ & $1.03-1.24$ & $1.02-1.17$ \\
$\mathrm{AUC}_{0-t}$ & $1.01-1.17$ & $0.91-1.08$ \\
$\mathrm{AUC}_{0-\infty}$ & $1.01-1.17$ & $0.89-1.08$ \\
\hline
\end{tabular}

Bioequivalence interpretation requires the $90 \%$ confidence intervals to be within the acceptance criteria of $0.8-1.25$.

healthy volunteers and diabetes patients [7-9]; nevertheless, there are scanty reports addressing bioequivalence study of this formulation. One reports bioequivalence of two sustained release gliclazide tablet formulations after singleand multiple-dose regimens, however, only in the fasted condition [11]. With respect to international guidelines for bioequivalence study, the effect of food should be approved $[12,13]$. In this current work, we originate the bioequivalence study of two gliclazide MR, Glycon MR, and Diamicron MR, in healthy Thai volunteers in both fasted and fed conditions. Blood samples were collected over $72 \mathrm{~h}$ after oral administration and examined for pharmacokinetic characteristics. Analysis of bioequivalence for two products was evaluated as well as the effect of food on the drug absorption.

\section{Materials and Methods}

2.1. Study Design. The study was approved by the Research Ethics Committee of the Chiang Mai University, Thailand. The study was assigned in both fasted and fed conditions with a single-dose, two-treatment, two-period, and two-sequence crossover study. Volunteers were randomly allocated to two groups of equal number. Group no. 1 was administered with the test product, following by the reference product whereas Group no. 2 started with the reference product, following by the test product. Each volunteer received both products under fasted and fed conditions with a 2-week washout period. 


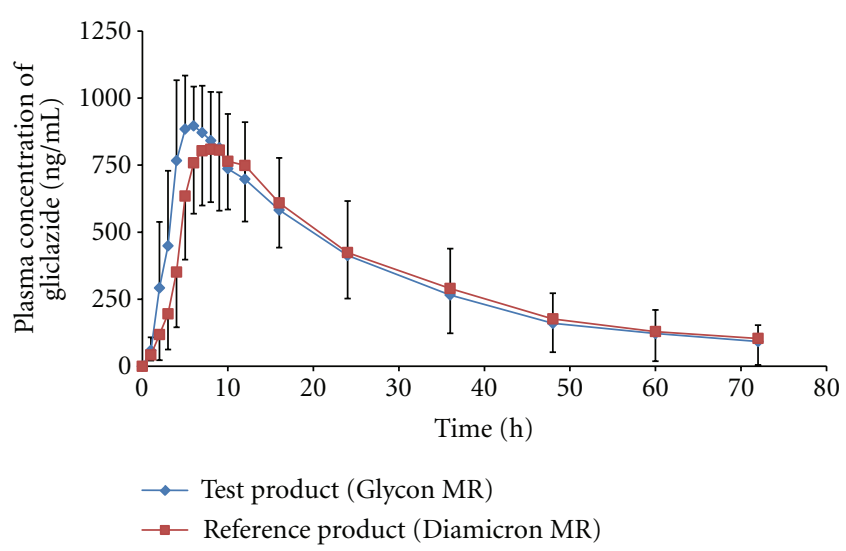

Figure 2: Mean plasma concentration of gliclazide after administration of $30 \mathrm{mg}$ gliclazide MR tablets of the test product, Glycon $\mathrm{MR}$, and the reference product, Diamicron MR, in 18 volunteers under fed condition.

2.2. Volunteers. Eighteen healthy Thai male volunteers, aged between 18-42 years old and the body mass index within 19$25 \mathrm{~kg} / \mathrm{m}^{2}$, were participated in the study. All volunteers were in a good health condition on the basis of medical history, physical examination, routine blood test, and possessing negative test for hepatitis B surface antigen (HBs-Ag), antihepatitis-C antibody (anti-HCV), and anti-HIV. Volunteers with known contraindication or hypersensitivity to gliclazide were excluded as well as those with known history of drug abuse, alcohol consumer, or cigarette smokers. No drug was allowed 1 month before the study period to avoid the effect of inducting or inhibiting hepatic metabolizing enzyme and the risk of drug interaction. The method and condition of the study were clearly informed to all volunteers, and the signed informed consent was obtained from all volunteers before entering the study.

2.3. Dosage and Drug Administration. Test product of $30 \mathrm{mg}$ gliclazide MR was Glycon MR (Lot no. J6GL00930, Siam Bheasach, Thailand, expiry 12/2008) and reference product was Diamicron MR (Lot no. 5L6232, Servier, France, expiry 11/2008).

Since gliclazide MR is an oral hypoglycemia agent, blood glucose level, blood pressure, and heart rate were monitored before drug administration. The blood glucose level was determined from fingertip using FINETOUCH lancing device and MEDISAFE blood glucose meter with test tip, (Terumo Corp. Tokyo, Japan). The blood pressure and heart rate were monitored using Digital Blood Pressure Monitor (model UA-767 Plus, A\&D Medical, Tokyo, Japan). The treatments for fasted and fed conditions are described below.

Fasted Condition. Each volunteer randomly received a 30mg gliclazide MR tablet either the test product or the reference product with $240-\mathrm{mL} 20 \%$ glucose solution after overnight fasting. After completion of the fasted condition,
TABLe 4: Pharmacokinetic characteristics of gliclazide from 18 volunteers following a single oral administration of $30 \mathrm{mg}$ gliclazide MR tablets under fed condition.

\begin{tabular}{lcc}
\hline $\begin{array}{l}\text { Pharmacokinetic } \\
\text { parameter }\end{array}$ & $\begin{array}{c}\text { Test product } \\
\text { (Glycon MR) }\end{array}$ & $\begin{array}{c}\text { Peference product } \\
\text { (Diamicron MR) }\end{array}$ \\
\hline$T_{\max }(\mathrm{h})$ & $5.56 \pm 1.62$ & $8.11 \pm 2.65$ \\
$C_{\max }(\mathrm{ng} / \mathrm{mL})$ & $996.48 \pm 193.85$ & $918.33 \pm 207.70$ \\
$\mathrm{AUC}_{0-t}(\mathrm{ng} \cdot \mathrm{h} / \mathrm{mL})$ & $24,338.87 \pm 9599.26$ & $24,074.37 \pm 8885.55$ \\
$\mathrm{AUC} C_{0-\infty}$ & $26,969.66 \pm 12098.68$ & $27,574.71 \pm 14049.22$ \\
$(\mathrm{ng} \cdot \mathrm{h} / \mathrm{mL})$ & $18.14 \pm 5.54$ & $18.74 \pm 7.76$ \\
$t_{1 / 2}(\mathrm{~h})$ & $0.04 \pm 0.01$ & $0.04 \pm 0.01$ \\
$K_{e}\left(\mathrm{~h}^{-1}\right)$ & &
\end{tabular}

TABle 5: $90 \%$ Confidence intervals of $C_{\max }, \mathrm{AUC}_{0-t}$, and $\mathrm{AUC}_{0-\infty}$ from the fed condition compared to the fasted conditions for the test product and reference product.

\begin{tabular}{|c|c|c|}
\hline \multirow{2}{*}{$\begin{array}{l}\text { Pharmacokinetic } \\
\text { parameter }\end{array}$} & \multicolumn{2}{|c|}{ 90\% Confidence interval } \\
\hline & $\begin{array}{l}\text { Test product } \\
\text { (Glycon MR) }\end{array}$ & $\begin{array}{l}\text { Reference product } \\
\text { (Diamicron MR) }\end{array}$ \\
\hline$C_{\max }$ & $0.93-1.09$ & $0.94-1.14$ \\
\hline $\mathrm{AUC}_{0-t}$ & $0.81-1.00$ & $0.90-1.08$ \\
\hline $\mathrm{AUC}_{0-\infty}$ & $0.80-1.01$ & $0.91-1.10$ \\
\hline
\end{tabular}

Bioequivalence interpretation requires the $90 \%$ confidence intervals to be within the acceptance criteria of $0.8-1.25$.

all volunteers were enrolled to the fed condition with a 2week washout period between two conditions.

Fed Condition. Each volunteer randomly received a 30-mg gliclazide MR tablet, either the test product or the reference product, at 10 min after receiving a Melander type standard breakfast as recommended in the earlier study [9].

2.4. Blood Samples Collection. For both studied conditions, volunteers were required to remain upright for $4 \mathrm{~h}$ after dosing. Glucose solution was then served at $2 \mathrm{~h}$ and a standard lunch was served at $4 \mathrm{~h}$ after dosing. A $5-\mathrm{mL}$ blood sample was collected at predose $(0 \mathrm{~h})$ and at $1,2,3,4,5,6,7$, $8,9,10,12,16,24,36,48,60$, and $72 \mathrm{~h}$ after dose.

2.5. Sample Preparation and HPLC Condition. Blood samples were centrifuged for $10 \mathrm{~min}$ at $3000 \mathrm{rpm}$ and the plasma was taken and immediately kept at $-20^{\circ} \mathrm{C}$ until assay. The drug was extracted from the plasma by solid phase extraction using a $50-\mu \mathrm{m}$ C18-E extraction column (Strata, Phenomenex, US.). The drug content was determined by HPLC with a UV detector (Shimadzu, Japan). Determination method was modified from the assay validation employed by Noguchi et al. [14]. Chromatographic system consisted of a $5-\mu \mathrm{m} \mathrm{C}-18$ reversed phase column equipped with a guard column of the same material (Inertsil ODS-3, GL Sciences, Japan) and the UV detector set at $230 \mathrm{~nm}$. Mobile phase was a mixture of $10 \mathrm{mM}$ perchloric acid ( $\mathrm{pH} 3.5$ )/acetonitrile/2propranolol/triethylamine $(500 / 230 / 230 / 0.5 \mathrm{v} / \mathrm{v})$. 


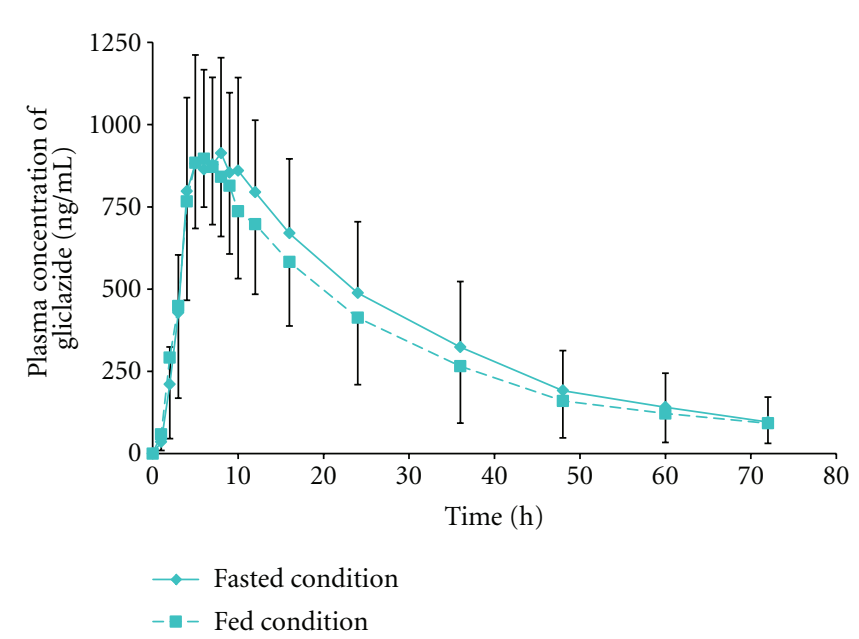

(a)

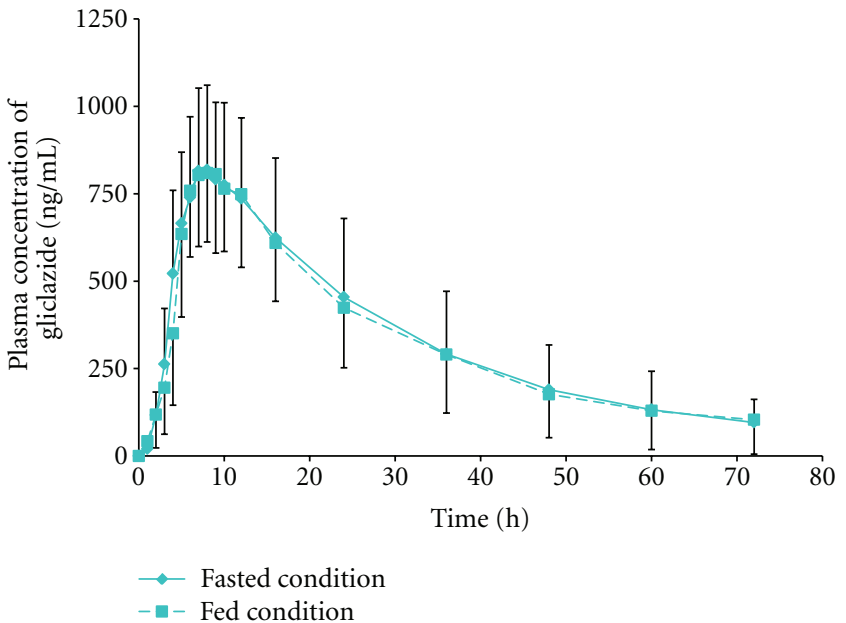

(b)

Figure 3: Comparison of gliclazide plasma concentrations under fasted and fed conditions after administration of $30 \mathrm{mg}$ gliclazide MR tablets of the test product, Glycon MR, (a) and the reference product, Diamicron MR, (b).

The system was an isocratic run with a flow rate of $1.0 \mathrm{~mL} / \mathrm{min}$ at $55^{\circ} \mathrm{C}$ using glibenclamide as an internal standard. A linear regression was performed to determine the drug concentration in the range of $10-2000 \mathrm{ng} / \mathrm{mL}\left(r^{2}=\right.$ 0.9994). The lower limit of quantitation was $10.0 \mathrm{ng} / \mathrm{mL}$ with the accuracy (\%) and precision (CV \%) of 114.26 and 14.99, respectively. The accuracy and precision for intraday assay validation were 104.79 and 8.56, respectively, and for interday assay validation were 99.85 and 8.88 , respectively. The phase extraction validation was presented by average accuracy and precision of $96.86 \%$ and $6.27 \%$ for a fasted unknown sample and $95.69 \%$ and $10.39 \%$ for a fed unknown sample, respectively. Less than $67 \%$ (4 out of 6 ) of OC samples were within $15 \%$ deviated of their respective nominal value.

\subsection{Statistical Methods and Data Analysis}

2.6.1. Pharmacokinetic Analysis. Maximum plasma concentration $\left(C_{\max }\right)$ and time to reach the peak concentration $\left(T_{\max }\right)$ as well as the time of the first measurable concentration $\left(T_{\mathrm{lag}}\right)$ were obtained directly from the plasma concentration-time profile. The area under the plasma concentration-time profile from time zero to infinity $\left(\mathrm{AUC}_{0-\infty}\right)$ and half-life $\left(t_{1 / 2}\right)$ were determined regarding the noncompartmental analysis. The slope of the terminal loglinear portion of the plasma concentration-time profile was determined by least-square regression to find an elimination rate constant $\left(K_{e}\right)$. The elimination half-life was calculated as $0.693 / K_{e}$. The area under the plasma concentrationtime profile from time zero to the last quantifiable point $\left(\mathrm{AUC}_{0-t}\right)$ was calculated using the trapezoidal rule and the area from the last quantifiable point to infinity $\left(\mathrm{AUC}_{t-\infty}\right)$ was determined as $C_{t} / K_{e}$. The $\mathrm{AUC}_{0-\infty}$ was the sum of $\mathrm{AUC}_{0-t}+\mathrm{AUC}_{t-\infty}$. Relative bioavailability $\left(F_{\text {rel }}\right)$ referred to the ratio of the mean value of the pharmacokinetic parameter of the test product to the reference product. The calculation was performed using TopFit Pharmacokinetic data analysis program.

2.6.2. Statistic Analysis for Bioequivalence. Bioequivalence analysis for the two products was determined by an analysis of variance (ANOVA) at $\alpha=0.05$ to determine statistical differences of $C_{\max }, \mathrm{AUC}_{0-t}$, and $\mathrm{AUC}_{0-\infty}$ which represented the extent and rate of drug absorption. Statistic analysis of $C_{\max }$ and AUC was performed on the logarithmically ( $\left.\mathrm{Ln}\right)$ transformed data. The $90 \%$ confidence interval (CI) for the ratio of the test product to the reference product based on Ln-transformed data was interpreted.

Statistical evaluation for the effect of food was performed by comparing $C_{\max }, T_{\max }, \mathrm{AUC}_{0-t}$, and $\mathrm{AUC}_{0-\infty}$ from the fasted and fed conditions using ANOVA. The magnitude of the difference between fasted and fed conditions was calculated as $90 \%$ CI of the ratio (fed/fasted) using the residual variance of the three-way ANOVA with the reference as the fasted condition. Bioequivalence interpretation requires the $90 \% \mathrm{CI}$ of the $C_{\max }, \mathrm{AUC}_{0-t}$, and $\mathrm{AUC}_{0-\infty}$ to be within the acceptance criteria of 0.8-1.25 (CDER 2002, CDER 2003).

\section{Results and Discussion}

3.1. Volunteer Demography and Safety. Eighteen healthy Thai male volunteers participated in the study. Their mean values of age, weight, height, and body mass index were 28.61 $\pm 6.63 \mathrm{yr}, 64.23 \pm 5.00 \mathrm{~kg}, 1.69 \pm 0.04 \mathrm{~m}$, and $22.38 \pm$ $1.65 \mathrm{~kg} / \mathrm{m}^{2}$, respectively. Demographic characteristics of the volunteers categorized into group no. 1 and group no. 2 are summarized in Table 1. The minimal predose blood glucose level was $75 \mathrm{mg} / \mathrm{dL}$. The dose regimen was well tolerated in all volunteers. There was no complaint on the therapy or presence of sign and symptom of hypoglycemia. Three volunteers had fever, sore throat, and running nose on the 
third visit of the study while one volunteer had stuffy nose and running nose on the forth visit. Necessary treatment was provided.

3.2. Pharmacokinetics and Bioequivalence under Fasted Condition. The plots of gliclazide plasma concentrations versus time under the fasted condition are showed in Figure 1 and pharmacokinetic characteristics are summarized in Table 2. The test product gave slightly greater AUC with higher $C_{\max }$ and longer $T_{\max }$ than the reference product. Eight volunteers obtained higher $C_{\max }$ for the test product compared to the reference product $\left(F_{\text {rel }}>125 \%\right)$ while two volunteers had lower $C_{\max }$ for the test product compared to the reference product $\left(F_{\text {rel }}<80 \%\right)$ and the rest obtained comparable values.

The $T_{\text {lag }}$ of the two products varied between $1-2 \mathrm{~h}$ and were within the time range reported previously $[8,9]$. The range of $T_{\max }$ of the test product and reference product were $4-16 \mathrm{~h}$ and $4-12 \mathrm{~h}$, respectively. Similarly, the median $T_{\max }$ of the test product $(8.5 \mathrm{~h})$ was slightly longer than those of the reference product $(7.0 \mathrm{~h})$. The median $T_{\max }$ obtained from this study was relatively longer than the earlier report in the range of 4-10 h [9]. However, the mean values of $C_{\max }, \mathrm{AUC}_{0-t}$, and $\mathrm{AUC}_{0-\infty}$ for the test product were not significantly different from those of the reference product and the $F_{\text {rel }}$ values based on $C_{\max }, \mathrm{AUC}_{0-t}$, and $\mathrm{AUC}_{0-\infty}$ were $115.5 \%, 111.4 \%$ and $111.2 \%$, respectively. The $t_{1 / 2}$ values of the test product and reference product were similar and comparable to those values of $12-17 \mathrm{~h}$ reported previously [9].

Table 3 summarizes the values of $90 \% \mathrm{CI}$ of $C_{\max }$, $\mathrm{AUC}_{0-t}$, and $\mathrm{AUC}_{0-\infty}$ for bioequivalence evaluation. The values of all parameters were within the acceptance criteria of $0.8-1.25$, indicating the bioequivalence of these two products under the fasted condition.

3.3. Pharmacokinetics and Bioequivalence under Fed Condition. Figure 2 depicts mean plasma concentration versus time profiles under the fed condition and the corresponding pharmacokinetic characteristics are summarized in Table 4. The profile of the test product showed slightly higher $C_{\max }$ and shorter $T_{\max }$ than the reference product. Five volunteers gave higher $C_{\max }$ for the test product compared to the reference product $\left(F_{\text {rel }}>125 \%\right)$ while the rest obtained comparable values.

Similar to the fasted condition, the $T_{\mathrm{lag}}$ of the two products varied between 1-2 $\mathrm{h}$. The $T_{\max }$ of the test product was shorter than that of the reference product with the median values of $5 \mathrm{~h}$ and $8 \mathrm{~h}$, respectively. However, there is no significant difference among the values of $C_{\max }, \mathrm{AUC}_{0-t}$ and $\mathrm{AUC}_{0-\infty}$ between the test product and reference product. The $F_{\text {rel }}$ values were $110.5 \%, 101.3 \%$, and $100.4 \%$ for $C_{\max }$, $\mathrm{AUC}_{0-t}$, and $\mathrm{AUC}_{0-\infty}$, respectively. The mean $t_{1 / 2}$ values of the test product and reference product were similar which slightly longer than the earlier report [9]. All 90\% CI values of $C_{\max }, \mathrm{AUC}_{0-t}$, and $\mathrm{AUC}_{0-\infty}$ listed in Table 3 are within the acceptance criteria, indicating that the two products were bioequivalent under the fed condition.
3.4. Effect of Food. Comparison of gliclazide plasma concentrations under fasted and fed conditions is illustrated in Figure 3. The profiles of the reference product in both conditions were comparable whereas the profile of the test product under the fed condition gave the faster $T_{\max }$ of $5.6 \mathrm{~h}$ compared to $8.2 \mathrm{~h}$ under the fasted condition. This result is in agreement with the previous report conducted by Delrat et al. [9] (2002) where the $C_{\max }$ under fed condition $(6 \mathrm{~h})$ is obtained earlier than the fasted condition $(7 \mathrm{~h})$. However, there is no significant difference in the values of $C_{\max }, \mathrm{AUC}_{0-t}$ and $\mathrm{AUC}_{0-\infty}, t_{1 / 2}$, and $K_{\mathrm{e}}$ for both test product and reference product under the fasted and fed conditions.

Table 5 summarizes the $90 \%$ CIs of the $C_{\max }, \mathrm{AUC}_{0-t}$ and $\mathrm{AUC}_{0-\infty}$ obtained under the fasted and fed conditions for the test product and reference product. Considering the acceptance criteria of $0.80-1.25$, all $90 \%$ CI values were within the criteria which indicates the insignificance of the food effect on the administration of gliclazide MR tablets from both products.

The results of this study demonstrated that the test product, Glycon MR, and the reference product, Diamicron MR were bioequivalent and may be used as an evidence for physicians to select the more cost-effective preparation of the modified-release gliclazide tablets.

\section{Conclusions}

Bioequivalence of two products of modified-release gliclazide tablets was studied at the single dose of $30 \mathrm{mg}$. Both products were well tolerated after oral administration, and food had no influence on their bioavailability. Pharmacokinetic results and statistical analysis revealed the $90 \% \mathrm{CI}$ values of $C_{\max }$, $\mathrm{AUC}_{0-t}$, and $\mathrm{AUC}_{0-\infty}$ in the acceptation criteria, indicating the bioequivalence of the test product, Glycon MR, and the reference product, Diamicron MR. The products can be interchangeable and administered without regard to meals.

\section{Acknowledgments}

This work was supported by Pharma Nueva Co., Ltd, Thailand. All authors do not have a direct financial relation with the commercial identities mentioned in the paper.

\section{References}

[1] D. B. Campbell, R. Lavielle, and C. Nathan, "The mode of action and clinical pharmacology of gliclazide: A review," Diabetes Research and Clinical Practice, vol. 14, supplement 2, pp. S21-S36, 1991.

[2] K. J. Palmer and R. N. Brogden, "Gliclazide_-an update of its pharmacological properties and therapeutic efficacy in noninsulin-dependent diabetes mellitus," Drugs, vol. 46, no. 1, pp. 92-125, 1993.

[3] K. G. Alberti, "Gliclazide: review of metabolic and vascular action," Diabète \& Métabolisme, vol. 20, no. 3, part 2, pp. 341348, 1994 (French).

[4] P. E. Jennings, "From hemobiology to vascular disease: a review of the potential of gliclazide to influence the pathogenesis of diabetic vascular disease," Journal of Diabetes and 
its Complications, vol. 8, no. 4, pp. 226-230, 1994.

[5] G. Schernthaner, "Gliclazide modified release: a critical review of pharmacodynamic, metabolic, and vasoprotective effects," Metabolism, vol. 52, no. 8, supplement 1, pp. 29-34, 2003.

[6] A. Harrower, "Gliclazide modified release: from oncedaily administration to 24-hour blood glucose control," Metabolism, vol. 49, no. 10, supplement 2, pp. 7-11, 2000.

[7] P. Drouin, "Diamicron $囚 M R$ once daily is effective and well tolerated in type 2 diabetes: a double-blind, randomized, multinational study," Journal of Diabetes and its Complications, vol. 14, no. 4, pp. 185-191, 2000.

[8] J. K. McGavin, C. M. Perry, and K. L. Goa, "Gliclazide modified release," Drugs, vol. 62, no. 9, pp. 1357-1364, 2002.

[9] P. Delrat, M. Paraire, and R. Jochemsen, "Complete bioavailability and lack of food-effect on pharmacokinetics of gliclazide $30 \mathrm{mg}$ modified release in healthy volunteers," Biopharmaceutics and Drug Disposition, vol. 23, no. 4, pp. 151-157, 2002.

[10] F. Ishibashi and S. Takashina, "The effect of timing on gliclazide absorption and action," Hiroshima Journal of Medical Sciences, vol. 39, no. 1, pp. 7-9, 1990.

[11] J. F. Yang, G. L. Wei, R. Lu, C. X. Liu, B. Z. Zheng, and P. Feng, "Bioavailability of gliclazide sustained release tablet in healthy volunteers," Asian Journal of Pharmacodynamics and Pharmacokinetics, vol. 6, no. 2, pp. 153-160, 2006.

[12] Center for Drug Evaluation and Research (CDER), Guidance for Industry, Food-Effect Bioavailability and Fed Bioequivalence Studies, US FDA, 2002.

[13] Center for Drug Evaluation and Research (CDER), Guidance for Industry, Bioavailability and Bioequivalence Studies for Orally Administered Drug Products-General Considerations, US FDA, 2003.

[14] H. Noguchi, N. Tomita, S. Naruto, and S. Nakano, "Determination of gliclazide in serum by high-performance liquid chromatography using solid-phase extraction," Journal of Chromatography, vol. 583, no. 2, pp. 266-269, 1992. 

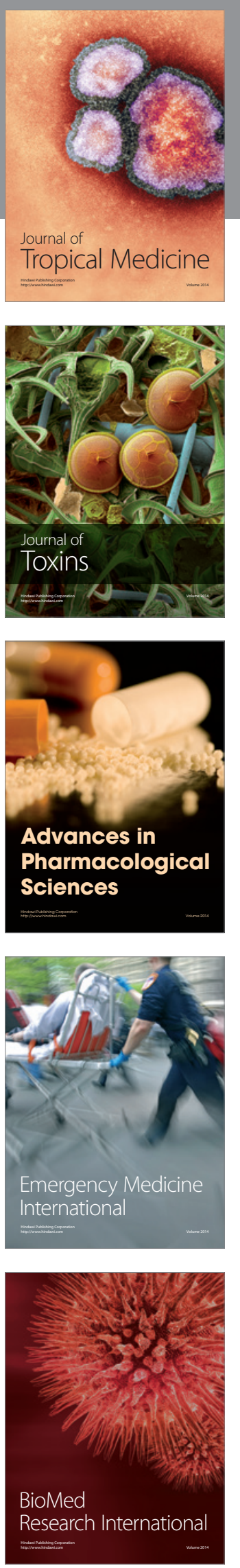
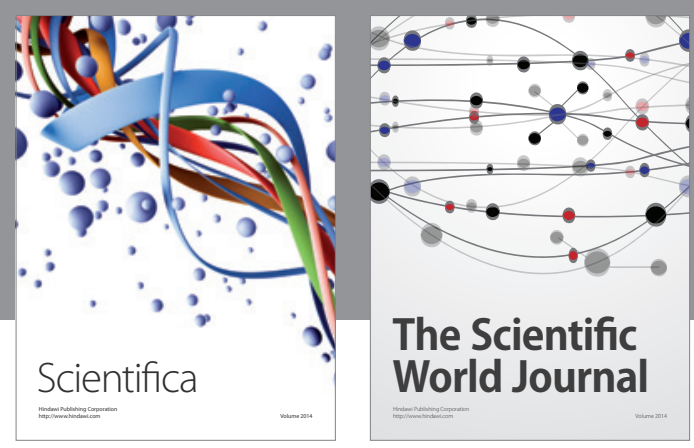

The Scientific World Journal
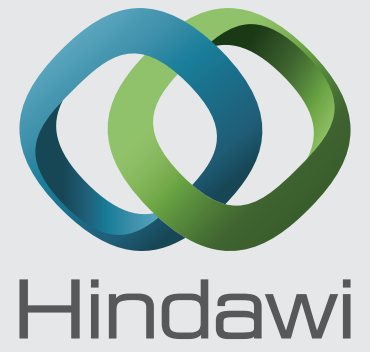

Submit your manuscripts at

http://www.hindawi.com
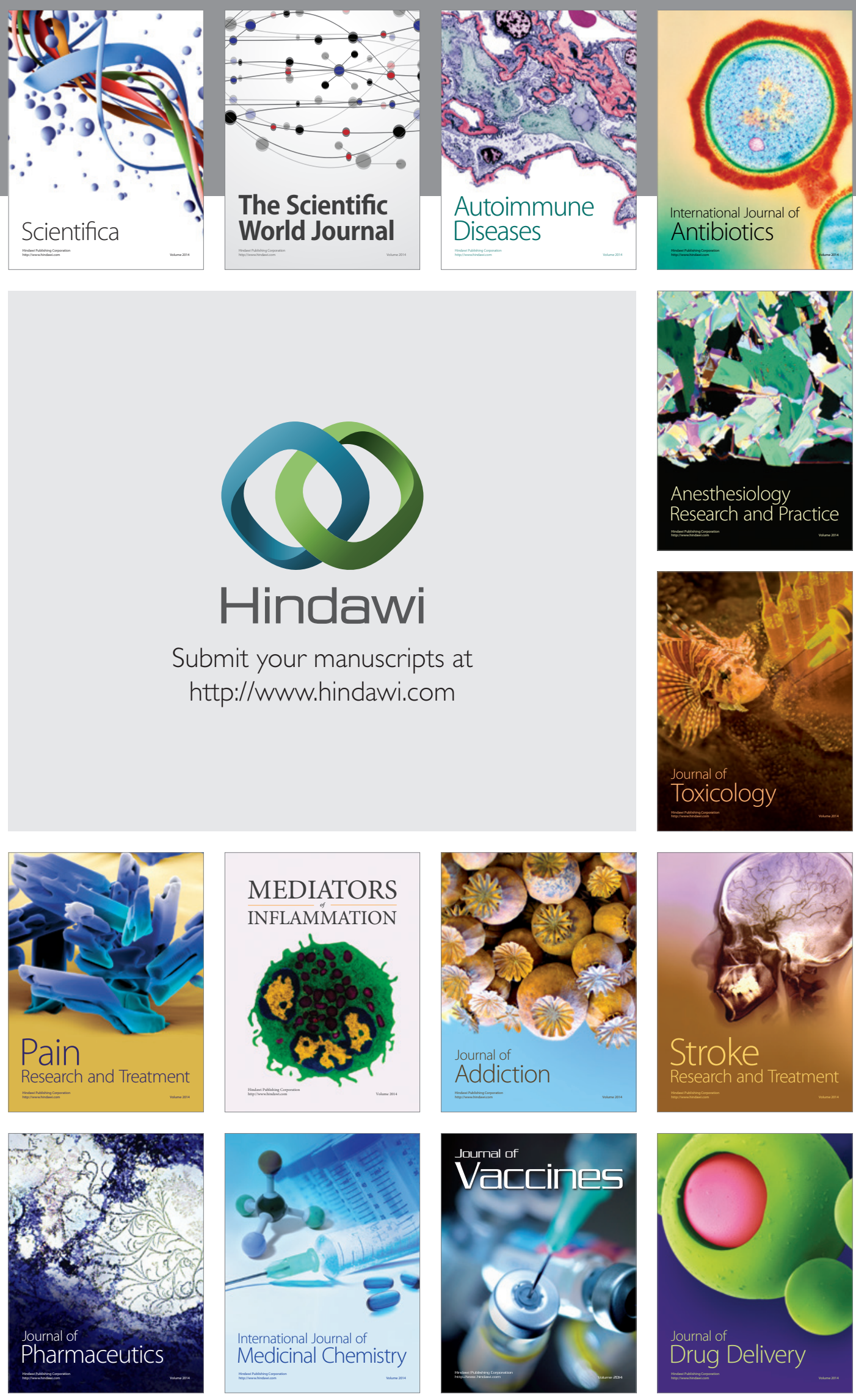